\title{
Occurrence of antibiotics in eight sewage treatment plants in Beijing, China
}

\author{
Lihong Gao ${ }^{\mathrm{a}, \mathrm{b}}$, Yali Shi ${ }^{\mathrm{a}}$, Wenhui $\mathrm{Li}^{\mathrm{a}}$, Hongyun $\mathrm{Niu}^{\mathrm{a}}$, Jiemin Liu ${ }^{\mathrm{b}}$, Yaqi Cai ${ }^{\mathrm{a}, *}$ \\ ${ }^{a}$ State Key Laboratory of Environmental Chemistry and Ecotoxicology, Research Center for Eco-Environmental Sciences, Chinese Academy of Sciences, Beijing 100085, China \\ ${ }^{\mathrm{b}}$ Civil and Environment Engineering School, University of Science and Technology Beijing, Beijing 100083, China
}

\section{A R T I C L E I N F O}

\section{Article history:}

Received 31 August 2011

Received in revised form 9 November 2011

Accepted 10 November 2011

Available online 6 December 2011

\section{Keywords:}

Antibiotics

Occurrence

STPs

Removal efficiency

Sludge

Seasonal variation

\begin{abstract}
A B S T R A C T
The occurrence, removal efficiency and seasonal variation of 22 antibiotics, including eight fluoroquinolones, nine sulfonamides and five macrolides, were investigated in eight sewage treatment plants (STPs) in Beijing, China. A total of 14 antibiotics were detected in wastewater samples, with the maximum concentration being $3.1 \mu \mathrm{g} \mathrm{L}^{-1}$ in the influent samples and $1.2 \mu \mathrm{g} \mathrm{L}^{-1}$ in the effluent samples. The most frequently detected antibiotics were ofloxacin, norfloxacin, sulfadiazine, sulfamethoxazole, erythromycin and roxithromycin; of these, the concentration of ofloxacin was the highest in most of the influent and effluent samples. Eighteen antibiotics were detected in the sludge samples, with concentrations ranging from $1.0 \times 10^{-1}$ to $2.1 \times 10^{4} \mu \mathrm{g} \mathrm{kg}^{-1}$. The dominant antibiotics found in the sludge samples were the fluoroquinolones, with ofloxacin having the highest concentration in all the sludge samples. The antibiotics could not be removed completely by the STPs, and the mean removal efficiency ranged from -34 to $72 \%$. Of all the antibiotics, the fluoroquinolones were removed comparatively more efficiently, probably due to their adsorption to sludge. Seasonal variation of the antibiotics in the sludge samples was also studied. The concentrations of antibiotics in winter were higher than in spring and autumn. Since the total levels of the fluoroquinolones detected in the influent samples were lower than the predicted no-effect concentration (PNEC) of $8.0 \mu \mathrm{g} \mathrm{L}^{-1}$, the residues of these antibiotics would be unlikely to have adverse effects on microorganisms involved in sewage treatment processes.
\end{abstract}

(c) 2011 Elsevier Ltd. All rights reserved.

\section{Introduction}

Pharmaceutical chemicals, including antibiotics, are widely used to treat and/or prevent diseases in humans and animals, as well as to promote the growth of animals in livestock and aquaculture operations (Kümmerer, 2009). Several studies have documented that antibiotics are not completely metabolized in the body and thus are excreted into the environment unchanged or in the form of their components via urine and feces (McArdell et al., 2003; Ternes et al., 2004; Löffler et al., 2005; Loganathan et al., 2009). Considerable amounts of antibiotics in the environment may also originate from the disposal of unused medicine. Antibiotics have been detected in municipal sewage (Karthikeyan and Meyer, 2006; Zorita et al., 2009), hospital wastewater (Lindberg et al., 2004), surface water (Golet et al., 2002; Jiang et al., 2011), groundwater (Lindsey et al., 2001), and as well as in soil, sediment and sludge samples (Díaz-Cruz and Barceló, 2005; Göbel et al., 2005; Kim and Carlson, 2007).

The greatest concern about antibiotics in the environment is the creation of the resistance of bacterial strains to antibiotics. Previous

\footnotetext{
* Corresponding author. Tel./fax: +86 1062849182.

E-mail address: caiyaqi@rcees.ac.cn (Y. Cai).
}

studies have shown that bacteria isolated from sewage reactors exhibit resistance to some antibiotics including erythromycin, ciprofloxacin, tetracycline, trimethoprim and ampicillin (Costanzo et al., 2005). Trimethoprim- and sulfonamide-resistant bacteria have been found in rivers of the United States (Khetan and Collins, 2007). There is also the concern that antibiotic residues in the environment can have adverse effects on various organisms. Ciprofloxacin has the potential to affect the structure and function of attached and suspended algal communities in natural freshwater (Wilson et al., 2003). Additionally, veterinary antibiotics can lead to oxidative damage in the liver cells of rainbow trout (Oncorhynchus mykiss) (Gagné et al., 2006).

For human-use antibiotics, the main entry route into the environment is via sewage treatment plants (STPs). Because of different antibiotic usage patterns, the species and concentrations of antibiotics found in STPs varies from country to country and from plant to plant. Several studies (Lindberg et al., 2005; Castiglioni et al., 2006; Loganathan et al., 2009) have demonstrated that the antibiotics found in STPs are not eliminated completely; removal efficiency can vary and is affected not only by compound-specific properties, but also by factors concerning specific STPs such as treatment process, hydraulic retention time (HRT) and solid retention time (SRT). Due to the poor removal efficiency, wastewater from STPs is a major source of antibiotics in the aquatic environment. 
In recent years, there have been a few studies investigating the occurrence and elimination of antibiotics in the environment in China. Most of these (Xu et al., 2007; Gulkowska et al., 2008; Lin et al., 2009; Chang et al., 2010; Li and Zhang, 2011) focused on the occurrence of antibiotics in wastewater and the efficiency of the removal of these antibiotics by STPs. However, there have been almost no studies in China on the concentration of antibiotics in sludge. The aim of this study was to investigate the occurrence and elimination of 22 antibiotics at eight STPs in Beijing, China. Wastewater samples, including raw influent and secondary effluent samples, as well as final sludge samples, were studied, along with the seasonal variation of the antibiotics in the sludge samples and the potential toxic effects of fluoroquinolones on microorganisms.

\section{Materials and methods}

\subsection{Materials and reagents}

Eighteen antibiotic standards (eight fluoroquinolones, five sulfonamides and five macrolides) including ofloxacin (OFL), norfloxacin (NOR), ciprofloxacin (CIP), sarafloxacin hydrochloride (SAR), fleroxacin (FLE), lomefloxacin hydrochloride (LOM), difloxacin hydrochloride (DIF), enrofloxacin (ENR), sulfadiazine (SD), sulfamerazin (SMR), sulfadimethoxine (SDM), sulfisoxazole (SIA), sulfamonomethoxine (SMM), erythromycin A dihydrate (ERY), roxithromycin (ROX), josamycin (JOS), tylosin tartrate (TYL) and spiramycin (SPI) were purchased from Sigma-Aldrich (USA). Three sulfonamide standards, sulfathiazole (ST), sulfapyridine (SPD) and sulfamethoxazole (SMX) were purchased from Tokyo Kasei Kogyo Co., Ltd. (Tokyo, Japan), and sulfamethazine (SMZ) was purchased from Acros Organics (USA). Surrogate standards norfloxacin- $\mathrm{d}_{5}$ $\left(\right.$ NOR- $\left.d_{5}\right)$, ofloxacin- $d_{3}\left(O F L-d_{3}\right)$ and sarafloxacin- $d_{8}\left(S A R-d_{8}\right)$ were obtained from Sigma-Aldrich (USA). Another four surrogate standards, sulfamethoxazole- $\mathrm{d}_{4} \quad\left(\mathrm{SMX}-\mathrm{d}_{4}\right)$, sulfamethazine- $\mathrm{d}_{4}$ $\left(\right.$ SMZ- $\left.\mathrm{d}_{4}\right)$, spiramycin I-d $\mathrm{d}_{3}\left(\mathrm{SPI} \mathrm{I}-\mathrm{d}_{3}\right)$ and erythromycin- ${ }^{13} \mathrm{C}-\mathrm{d}_{3}$ (ERY ${ }^{13} \mathrm{C}-\mathrm{d}_{3}$ ) were obtained from Toronto Research Chemicals (Canada). All these antibiotics were prepared in methanol and stored at $-7{ }^{\circ} \mathrm{C}$ in a light free environment. HPLC grade methanol and acetonitrile were provided by Fisher Scientific (New Jersey, USA). Ammonium hydroxide (50\%, V/V) and ammonium formate (99\%) were obtained from Alfa Aesar (USA), and formic acid (98\%) was obtained from Fluka (USA). Ultra-pure water was produced by a Milli-Q water purification system (Millipore, USA).

\subsection{Sampling}

A total of 51 samples including 8 influent samples, 8 effluent samples and 35 sludge samples were collected from eight STPs in Beijing at five individual time points (January 15, May 28 and September 24 in 2008, October 15 in 2009, and May 13 in 2010). Influent and effluent samples were only collected on May 13 in 2010. Most of the STPs studied employ conventional activated sludge treatments to remove biologically degradable organic materials. Three plants (B, E and $G$ ) use an anaerobic/anoxic/oxic $\left(A^{2} / O\right)$ activated sludge process and two plants ( $\mathrm{F}$ and $\mathrm{H})$ use cyclic activated sludge technology (CAST). STP D employs an oxidation ditch (OD) and STP $A$ uses an anoxic/oxic (A/O) activated sludge process. On the basis of the $A^{2} / O$ process, STP $C$ uses cilium nutrient removal (CNR) technology to enhance the nitrogen and phosphorus removal. These STPs have different treatment capacities (average daily flow from 0.01 to 1.0 million $\mathrm{m}^{3} \mathrm{~d}^{-1}$ ) and serve different numbers of residents. Details about the STPs and samples are shown in Fig. S1, and Tables S1 and S2.
The $24 \mathrm{~h}$ composite influent and effluent samples were collected using flow proportional samplers. All of the wastewater samples were collected in polypropylene bottles $(500 \mathrm{~mL})$ rinsed with water and methanol and dried in advance. Immediately after being transported to the laboratory, the samples were stored at $4{ }^{\circ} \mathrm{C}$ and pretreated within 1 week.

Sludge samples were collected in polyethylene bags and immediately freeze-dried after being delivered to the laboratory. The sludge was ground and sieved to smaller than $0.44 \mathrm{~mm}$, and then stored at $-20^{\circ} \mathrm{C}$ until analysis.

\subsection{Methods}

Analytical procedures for the 22 antibiotics in the wastewater and sludge samples were developed based on EPA Method 1694 USEPA, 2007) with some modifications. Water samples were extracted and cleaned by solid phase extraction (SPE) with an Oasis HLB cartridge (6 cc, 200 mg; Waters Corp., Milford, USA). Sludge samples were extracted by ultrasonic technology, and then cleaned by SPE with an HLB cartridge. Detailed pretreatment information is listed in the Supplementary materials.

The antibiotics were analyzed by an HPLC system consisting of a P680 pump and an UltiMate 3000 autosampler (Dionex, USA) coupled with an API 3200 triple quadruple mass spectrometer equipped with an electrospray ion source (ESI) (Applied Biosystems-Sciex, USA). The separation of the analytes was carried out on an XTerra MS $\mathrm{C}_{18}$ column $(2.1 \mathrm{~mm} \times 100 \mathrm{~mm}$ i.d., $3.5 \mu \mathrm{m})$ (Waters Corp., USA) at a flow rate of $0.2 \mathrm{~mL} \mathrm{~min}^{-1}$. Mass spectrometric analysis was performed in a positive ion mode with multiple reaction monitoring (MRM). Detailed information is listed in the Supplementary materials.

\subsection{Quality control}

The calibration curve was prepared within a wide range of concentrations $\left(0.05-500 \mu \mathrm{g} \mathrm{L}^{-1}\right)$ to reveal strong linearity $\left(r^{2}>0.99\right)$, except for ERY $\left(r^{2}=0.9810\right)$. The limits of detection (LOD) of this method, defined as the lowest concentration producing a signalto-noise ratio $(\mathrm{S} / \mathrm{N})$ of 3 , were $0.01-0.25 \mathrm{ng} \mathrm{L}^{-1}$ for wastewater and $0.02-0.5 \mu \mathrm{g} \mathrm{kg}^{-1}$ for sludge. Surrogates were used to compensate for the loss of analytes, and the relative recovery rates ranged from 57.4 to $138 \%$ for the spiked antibiotics in wastewater and $36.2-113 \%$ (except $207 \%$ for SD, $174 \%$ for ST, $160 \%$ for SPD and $147 \%$ for SMR) for sludge. The main reason for the high relative recovery rates of some compounds was their higher absolute recovery rates when compared with corresponding surrogates. The matrix also had an important impact on the recovery rates of these compounds. Standard deviations ranged from 2.4 to $15.6 \%$ for wastewater and $1.3-18.5 \%$ (except $31.0 \%$ for OFL) for sludge samples. Detailed information is listed in Table S4. During the analysis of each batch of samples, at least one blank should be prepared from ultra-pure water. In order to monitor the stability of the system, 10 injections for each standard solution $\left(1 \mu \mathrm{g} \mathrm{L}{ }^{-1}\right)$ are necessary to run during analysis.

\section{Results and discussion}

\subsection{Occurrence of selected antibiotics in wastewater samples}

Table 1 shows the concentrations of selected antibiotics in influent and effluent samples from eight STPs. Among 22 analytes, 14 antibiotics including five fluoroquinolones, four sulfonamides and five macrolides were detected. Fluoroquinolones were most frequently detected in all wastewater samples, and OFL revealed the maximum concentration in all samples except in STP A effluent. 
Table 1

Concentrations ( $\mu \mathrm{g} \mathrm{L}^{-1}$ ) of antibiotics determined in influent and effluent samples.

\begin{tabular}{|c|c|c|c|c|c|c|c|c|c|c|}
\hline \multirow[t]{2}{*}{ Groups } & \multirow[t]{2}{*}{ Analytes } & \multirow[t]{2}{*}{ Samples } & \multicolumn{8}{|l|}{ STPs } \\
\hline & & & A & B & $\mathrm{C}$ & $\mathrm{D}$ & $\mathrm{E}$ & $\mathrm{F}$ & G & $\mathrm{H}$ \\
\hline \multirow[t]{10}{*}{ Fluoroquinolones } & \multirow[t]{2}{*}{ NOR } & Influent & 0.051 & 0.11 & 0.31 & 0.087 & 0.14 & 0.21 & 0.19 & 0.12 \\
\hline & & Effluent & 0.0094 & 0.036 & 0.056 & 0.045 & 0.13 & 0.20 & 0.070 & 0.075 \\
\hline & \multirow[t]{2}{*}{ CIP } & Influent & 0.015 & 0.14 & 0.059 & 0.14 & 0.036 & 0.069 & 0.058 & 0.057 \\
\hline & & Effluent & $\mathrm{nd}^{\mathrm{a}}$ & 0.0025 & 0.0095 & 0.015 & 0.023 & 0.055 & 0.021 & 0.031 \\
\hline & \multirow[t]{2}{*}{ FLE } & Influent & 0.016 & 0.043 & 0.039 & 0.027 & nd & 0.041 & 0.022 & 0.018 \\
\hline & & Effluent & 0.011 & 0.016 & nd & nd & 0.011 & 0.038 & nd & nd \\
\hline & \multirow[t]{2}{*}{ OFL } & Influent & 0.99 & 0.96 & 3.1 & 1.1 & 1.3 & 2.2 & 1.7 & 0.44 \\
\hline & & Effluent & 0.15 & 0.60 & 1.2 & 0.72 & 0.58 & 0.92 & 0.75 & 0.38 \\
\hline & \multirow[t]{2}{*}{ LOM } & Influent & 0.0056 & 0.050 & 0.041 & 0.14 & 0.017 & 0.18 & 0.077 & 0.039 \\
\hline & & Effluent & nd & 0.019 & nd & 0.0019 & 0.028 & 0.14 & 0.012 & nd \\
\hline \multirow[t]{8}{*}{ Sulfonamides } & \multirow[t]{2}{*}{ SMX } & Influent & 0.42 & 0.49 & 0.72 & 0.46 & 0.41 & 1.0 & 0.63 & 0.29 \\
\hline & & Effluent & 0.44 & 0.22 & 0.46 & 0.34 & 0.25 & 0.38 & 0.30 & 0.13 \\
\hline & \multirow[t]{2}{*}{ SPD } & Influent & 0.27 & 0.22 & 0.53 & 0.36 & 0.40 & 0.47 & 0.43 & 0.11 \\
\hline & & Effluent & 0.33 & 0.11 & 0.33 & 0.13 & 0.24 & 0.26 & 0.30 & 0.036 \\
\hline & \multirow[t]{2}{*}{ SMZ } & Influent & 0.015 & 0.0065 & 0.010 & 0.0078 & 0.0044 & 0.015 & 0.018 & 0.0032 \\
\hline & & Effluent & 0.0071 & 0.0025 & 0.0088 & 0.0031 & 0.0040 & 0.0064 & 0.011 & 0.0016 \\
\hline & \multirow[t]{2}{*}{ SD } & Influent & 0.73 & 0.55 & 1.0 & 1.3 & 0.65 & 2.0 & 0.68 & 0.38 \\
\hline & & Effluent & 0.48 & 0.12 & 0.30 & 0.27 & 0.24 & 0.56 & 0.33 & 0.14 \\
\hline \multirow[t]{10}{*}{ Macrolides } & \multirow[t]{2}{*}{ SPI } & Influent & nd & 0.0092 & 0.027 & 0.013 & 0.011 & 0.014 & 0.16 & nd \\
\hline & & Effluent & nd & 0.0061 & nd & 0.0038 & 0.0073 & nd & 0.032 & nd \\
\hline & \multirow[t]{2}{*}{ JOS } & Influent & 0.0014 & 0.0010 & 0.0018 & 0.0020 & 0.0011 & 0.0010 & 0.0027 & nd \\
\hline & & Effluent & 0.0015 & nd & 0.0010 & 0.0010 & 0.0010 & nd & 0.0020 & nd \\
\hline & \multirow[t]{2}{*}{ TYL } & Influent & nd & 0.0040 & 0.0029 & 0.0023 & 0.0012 & 0.0021 & 0.0019 & nd \\
\hline & & Effluent & nd & 0.0028 & nd & 0.0012 & 0.0019 & nd & 0.0030 & nd \\
\hline & \multirow[t]{2}{*}{ ERY } & Influent & 0.29 & 0.18 & 0.27 & 0.26 & 0.17 & 0.52 & 0.26 & 0.13 \\
\hline & & Effluent & 0.17 & 0.051 & 0.27 & 0.12 & 0.30 & 0.26 & 0.27 & 0.064 \\
\hline & \multirow[t]{2}{*}{ ROX } & Influent & 0.087 & 0.13 & 0.18 & 0.085 & 0.067 & 0.16 & 0.11 & 0.26 \\
\hline & & Effluent & 0.14 & 0.084 & 0.12 & 0.054 & 0.19 & 0.24 & 0.15 & 0.36 \\
\hline
\end{tabular}

a Not detected.

The concentrations of OFL and NOR in influent samples were in the range of $0.44-3.1 \mu \mathrm{g} \mathrm{L}^{-1}$ and $0.051-0.31 \mu \mathrm{g} \mathrm{L}^{-1}$, respectively. A similar concentration range for NOR has been recorded as 0.11-0.46 $\mu \mathrm{g} \mathrm{L}^{-1}$ (Gulkowska et al., 2008) in influent samples from five STPs in Hong Kong and Shenzhen and 0.054-0.263 $\mu \mathrm{g} \mathrm{L}^{-1}(\mathrm{Xu}$ et al., 2007) in influent samples from four STPs in the Pearl River Delta. However, lower concentration ranges such as $0.028-0.32 \mu \mathrm{g} \mathrm{L}^{-1}$ for OFL and $0.018-0.027 \mu \mathrm{g} \mathrm{L}^{-1}$ for NOR in STP influent samples in Sweden have been reported (Zorita et al., 2009). In addition, the reported concentration of CIP $\left(0.028-0.32 \mu \mathrm{g} \mathrm{L}^{-1}\right)$ is similar to our result $\left(0.015-0.14 \mu \mathrm{g} \mathrm{L}^{-1}\right)$. In contrast, in Spain, much higher concentrations of OFL and CIP have been reported, with 0.848$5.29 \mu \mathrm{g} \mathrm{L}^{-1}$ for OFL and $0.160-13.6 \mu \mathrm{g} \mathrm{L}^{-1}$ for CIP (Rosal et al., 2010). In this study, the antibiotics were not completely eliminated by the employed treatment processes, especially OFL and NOR, due to their ubiquitous presence in the effluent samples. The highest concentration of fluoroquinolones in the effluent samples was detected at $1.2 \mu \mathrm{g} \mathrm{L}^{-1}$ for OFL in STP C.

In the eight STPs, four out of nine sulfonamides were detected in influent and effluent samples, and the concentrations were in the order of SD $>$ SMX $>$ SPD $>$ SMZ. The levels of SD and SMX were ranged in $0.38-2.0 \mu \mathrm{g} \mathrm{L}^{-1}$ and $0.29-1.0 \mu \mathrm{g} \mathrm{L}^{-1}$ in the influent samples, respectively; and this changed from 0.12 to $0.56 \mu \mathrm{g} \mathrm{L}^{-1}$ and from 0.13 to $0.46 \mu \mathrm{g} \mathrm{L}^{-1}$ in the effluent samples, respectively, which was consistent with the previously reported concentration $\left(1.38 \mu \mathrm{g} \mathrm{L}^{-1}\right)$ of SD in STP influent samples from Chongqing (Chang et al., 2010) and the concentration change range of SMX in raw influent $\left(0.23-0.57 \mu \mathrm{g} \mathrm{L}^{-1}\right)$ and in secondary effluent samples (0.13-0.84 $\mu \mathrm{g} \mathrm{L}^{-1}$ ) (Göbel et al., 2005). In addition, previous reports have also documented that the maximum concentrations of SMX in STP influent samples are $1.25 \mu \mathrm{g} \mathrm{L}^{-1}$ (Karthikeyan and Meyer, 2006) in Wisconsin (USA), $0.500 \mu \mathrm{g} \mathrm{L}^{-1}$ (Watkinson et al., 2007) in Australia and $0.674 \mu \mathrm{g} \mathrm{L}^{-1}$ (Lindberg et al., 2005) in Stockholm (Sweden).

ERY and ROX were the most frequently detected macrolides in all influent and effluent samples. The concentrations of ERY ranged from 0.13 to $0.52 \mu \mathrm{g} \mathrm{L}^{-1}$ in influents and from 0.051 to $0.30 \mu \mathrm{g} \mathrm{L}^{-1}$ in effluents. In some previous cases, ERY has been determined in the form of its dehydrated product, ERY- $\mathrm{H}_{2} \mathrm{O}$. The maximum concentrations of ERY or ERY- $\mathrm{H}_{2} \mathrm{O}$ in raw influents have been reported as $0.19 \mu \mathrm{g} \mathrm{L}^{-1}$ in Switzerland (Göbel et al., 2007), $0.81 \mu \mathrm{g} \mathrm{L}^{-1}$ in Hong Kong (Gulkowska et al., 2008), $1.2 \mu \mathrm{g} \mathrm{L}^{-1}$ in the US (Yu et al., 2006) and $2.31 \mu \mathrm{g} \mathrm{L}^{-1}$ in Spain (Rosal et al., 2010). ROX was another commonly detected macrolide in our study, with concentrations ranging from 0.067 to $0.26 \mu \mathrm{g} \mathrm{L}^{-1}$ in influents and from 0.054 to $0.36 \mu \mathrm{g} \mathrm{L}^{-1}$ in effluents. ERY and ROX were more abundant in effluents than in influents in our study, which is similar to that found in the Varese STP in Italy (Zuccato et al., 2010) and STPs in the Pearl River Delta, South China (Xu et al., 2007). The probable reason for this finding is due to the binding of ERY and ROX to sludge and the delayed release.

\subsection{Occurrence of selected antibiotics in sludge samples}

Table 2 presents the concentrations of selected antibiotics in sludge samples from eight STPs. Eighteen antibiotics including eight fluoroquinolones, five sulfonamides and five macrolides were detected in the sludge samples. Fluoroquinolones were the most frequently detected antibiotics in the sludge samples, and their concentrations were much higher than those for the other two 
Table 2

Concentrations ( $\mu \mathrm{g} \mathrm{kg}^{-1} \mathrm{dw}$ ) of antibiotics determined in sludge samples.

\begin{tabular}{|c|c|c|c|c|c|c|}
\hline Groups & Analytes & Max. $^{a}$ & Min. ${ }^{\mathrm{b}}$ & Mean & Med. ${ }^{c}$ & Freq. ${ }^{\mathrm{d}}(\%)$ \\
\hline \multirow[t]{8}{*}{ Fluoroquinolones } & NOR & $4.9 \times 10^{3}$ & $4.3 \times 10^{2}$ & $3.2 \times 10^{3}$ & $3.5 \times 10^{3}$ & 100 \\
\hline & CIP & $9.5 \times 10^{2}$ & $1.3 \times 10^{2}$ & $4.6 \times 10^{2}$ & $4.3 \times 10^{2}$ & 100 \\
\hline & DIF & $1.1 \times 10^{1}$ & $\mathrm{nd}^{\mathrm{e}}$ & $7.0 \times 10^{-1}$ & 9.1 & 9 \\
\hline & ENR & $9.5 \times 10^{1}$ & $1.0 \times 10^{-1}$ & $2.1 \times 10^{1}$ & $1.6 \times 10^{1}$ & 100 \\
\hline & FLE & $3.2 \times 10^{2}$ & 5.5 & $1.3 \times 10^{2}$ & $1.2 \times 10^{2}$ & 100 \\
\hline & OFL & $2.1 \times 10^{4}$ & $5.5 \times 10^{2}$ & $1.1 \times 10^{4}$ & $1.2 \times 10^{4}$ & 100 \\
\hline & LOM & $3.0 \times 10^{3}$ & $6.9 \times 10^{1}$ & $8.3 \times 10^{2}$ & $5.8 \times 10^{2}$ & 100 \\
\hline & SAR & $2.4 \times 10^{1}$ & nd & $7.0 \times 10^{-1}$ & $2.4 \times 10^{1}$ & 3 \\
\hline \multirow[t]{5}{*}{ Sulfonamides } & SMX & $4.5 \times 10^{1}$ & nd & $1.1 \times 10^{1}$ & 9.1 & 77 \\
\hline & SPD & $6.8 \times 10^{1}$ & 2.6 & $3.8 \times 10^{1}$ & $3.6 \times 10^{1}$ & 100 \\
\hline & SMZ & $6.1 \times 10^{1}$ & nd & 3.0 & 4.9 & 23 \\
\hline & SD & $7.0 \times 10^{1}$ & 3.2 & $2.8 \times 10^{1}$ & $2.2 \times 10^{1}$ & 100 \\
\hline & SMR & 3.7 & nd & $1.0 \times 10^{-1}$ & 3.7 & 3 \\
\hline \multirow[t]{5}{*}{ Macrolides } & SPI & $3.2 \times 10^{1}$ & nd & 7.8 & 7.0 & 83 \\
\hline & JOS & $3.0 \times 10^{-1}$ & nd & nd & $3.0 \times 10^{-1}$ & 3 \\
\hline & TYL & 6.1 & nd & $2.0 \times 10^{-1}$ & 3.7 & 6 \\
\hline & ERY & $7.1 \times 10^{2}$ & nd & $3.9 \times 10^{1}$ & $1.4 \times 10^{2}$ & 17 \\
\hline & ROX & $1.7 \times 10^{2}$ & 1.8 & $1.9 \times 10^{1}$ & 9.3 & 100 \\
\hline
\end{tabular}

\footnotetext{
a Maximum.

b Minimum.

c Median.

d Frequency.

e Not detected.
}

groups. The higher concentrations of fluoroquinolones in the influents and their stronger adsorption to the sludge than the other two classes of antibiotics may be the reason for their higher concentrations in the sludge samples. Solid-water distribution coefficient $\left(K_{\mathrm{d}}\right)$ is defined as a ratio of content in particle to that in water. Compared with other compounds, the relatively higher $K_{\mathrm{d}}$ value of fluoroquinolones indicates stronger adsorption to sludge (Okuda et al., 2009).

Among the fluoroquinolones, NOR, CIP, ENR, FLE, OFL and LOM were detected in all the sludge samples, while DIF and SAR were only present in $9 \%$ and $3 \%$ of the analyzed samples, respectively. The concentrations of OFL and NOR in the sludge samples ranged from $5.5 \times 10^{2}$ to $2.1 \times 10^{4} \mu \mathrm{g} \mathrm{kg}^{-1} \mathrm{dw}$ (dry weight basis) and from $4.3 \times 10^{2}$ to $4.9 \times 10^{3} \mu \mathrm{g} \mathrm{kg}^{-1} \mathrm{dw}$, respectively, which was several orders of magnitude higher than those of other compounds. The concentrations of OFL and NOR detected in this study were much higher than those detected in the Pearl River Delta, South China (OFL 165-886 $\mu \mathrm{g} \mathrm{kg}^{-1}$, NOR $40-372 \mu \mathrm{g} \mathrm{kg}^{-1}$ ) (Xu et al., 2007), and the concentrations of NOR were similar to those found in Sweden (NOR $1.0 \times 10^{2}$ to $4.2 \times 10^{3} \mu \mathrm{g} \mathrm{kg}^{-1} \mathrm{dw}$ ) (Lindberg et al., 2005). In the present study, the highest concentrations of OFL and NOR were found at STP C, and the lowest concentration of each fluoroquinolone was detected at STP $\mathrm{H}$, which possessed the least treatment capacity and the smallest number of served residents. Moreover, different treatment processes $\left(A^{2} / O+C N R\right.$ for STP $C$ and CAST for STP H) may be another important factor for different concentrations.

The concentrations of sulfonamides and macrolides in the sludge samples were relatively lower. Five sulfonamides were detected, and the average concentrations were in the order of $\mathrm{SPD}>\mathrm{SD}>\mathrm{SMX}>\mathrm{SMZ}>\mathrm{SMR}$. The concentrations of SPD and SD in the sludge samples ranged from 2.6 to $68 \mu \mathrm{g} \mathrm{kg}^{-1} \mathrm{dw}$, and from 3.2 to $70 \mu \mathrm{g} \mathrm{kg}^{-1} \mathrm{dw}$, respectively. SPD and SD were detected in all the sludge samples, while SMX, SMZ and SMR were present in 77, 23 and 3\% of the analyzed samples, respectively. Although macrolides were detected in all the sludge samples, their concentrations were low. The most frequently detected macrolide was ROX (100\%), followed by SPI (83\%). The concentration of ROX was changed from 1.8 to $1.7 \times 10^{2} \mu \mathrm{g} \mathrm{kg}^{-1} \mathrm{dw}$. ERY revealed the greatest concentration $\left(7.1 \times 10^{2} \mu \mathrm{g} \mathrm{kg}^{-1} \mathrm{dw}\right)$ at STP A, although it was only detected in $17 \%$ of the analyzed samples.

\subsection{Removal of antibiotics by STPS}

The removal efficiency of antibiotics was calculated from the analyte concentration in influent $\left(C_{\mathrm{in}}\right)$ and effluent $\left(C_{\mathrm{ef}}\right)$ : $\left[\left(C_{\mathrm{in}}-C_{\mathrm{ef}}\right) /\right.$ $\left.C_{\text {in }}\right] \times 100 \%$. As shown in Table 3 , the average removal efficiency of fluoroquinolones ranged from 48 to $72 \%$, slightly higher than those of sulfonamides (39-64\%) and macrolides ( -34 to $69 \%$ ).

The mean removal efficiency of OFL was $50 \%$, which was similar to the value (56\%) by the STPs in Sweden (Zorita et al., 2009) and lower than that (83\%) by the STP in Finland (Vieno et al., 2007). For NOR, the mean and maximum removal efficiency was 48 and $82 \%$, respectively. The mean removal efficiency of $67 \%$ for CIP in our study is higher than Rosal's observation (57.0\%) (Rosal et al., 2010), and lower than the mean removal efficiency of $84 \%$ by STPs in Finland (Vieno et al., 2007). In Sweden, the mean elimination degrees of OFL, NOR and CIP were estimated to be 86,87 and $87 \%$ (Lindberg et al., 2005), respectively. For fluoroquinolones, adsorption to sludge is a possible major elimination process for STPs although they are very hydrophilic and zwitterionic compounds (Xu et al., 2007). In the present study, the higher concentrations of fluoroquinolones in the sludge samples support the above conclusion.

In the present study, the removal efficiency of SD and SMX by the eight STPs investigated varied from 34 to $79 \%$ and from -5 to $62 \%$, respectively. The average removal efficiency of SD, SMX, SPD and SMZ was $64,40,39$, and $44 \%$, respectively. Similar removal efficiency of SD (20-82\%) has also been detected in four STPs from Taiwan (Lin et al., 2009) and in two STPs from the Pearl River Delta, with a removal efficiency of $50 \%$ (Xu et al., 2007). Meanwhile, the removal efficiency of SMX changed from 0 to $64 \%$, which is similar to our current results. Similar removal efficiency of SMX (71\% in summer and 0-84\% in winter) in STPs in Italy has also been reported (Castiglioni et al., 2006). The negative removal efficiency of SMX and SPD in STP A may be caused by the presence of metabolites in the influents, which can subsequently be transformed to their parent compounds during biological treatment (Göbel et al., 2007).

Compared with fluoroquinolones and sulfonamides, the removal efficiency of macrolides is lower. The mean removal efficiency of ERY was $24 \%$ (ranging from -74 to $73 \%$ ), which was similar to the reported removal efficiency (26\%) of ERY- $\mathrm{H}_{2} \mathrm{O}$ in four 
Table 3

Removal efficiency (\%) of antibiotics in eight STPs.

\begin{tabular}{|c|c|c|c|c|c|c|c|c|c|c|c|c|}
\hline Groups & Analytes & A & $\mathrm{B}$ & $\mathrm{C}$ & $\mathrm{D}$ & $E$ & $\mathrm{~F}$ & G & $\mathrm{H}$ & Max. $^{a}$ & Min. $^{\text {b }}$ & Mean \\
\hline \multirow[t]{6}{*}{ Fluoroquinolones } & NOR & 82 & 68 & 82 & 49 & 2 & 5 & 63 & 37 & 82 & 2 & 48 \\
\hline & CIP & 100 & 98 & 84 & 89 & 37 & 20 & 63 & 45 & 100 & 20 & 67 \\
\hline & FLE & 32 & 62 & 100 & 100 & & 8 & 100 & 100 & 100 & 8 & 72 \\
\hline & OFL & 85 & 38 & 63 & 34 & 54 & 58 & 57 & 13 & 85 & 13 & 50 \\
\hline & LOM & 100 & 61 & 100 & 99 & -60 & 23 & 84 & 100 & 100 & -60 & 63 \\
\hline & Mean & 80 & 65 & 86 & 74 & 8 & 23 & 73 & 59 & & & \\
\hline \multirow[t]{5}{*}{ Sulfonamides } & SMX & -5 & 56 & 36 & 25 & 41 & 62 & 52 & 56 & 62 & -5 & 40 \\
\hline & SPD & -22 & 51 & 38 & 63 & 40 & 45 & 29 & 68 & 68 & -22 & 39 \\
\hline & SMZ & 52 & 62 & 12 & 60 & 9 & 59 & 42 & 51 & 62 & 9 & 44 \\
\hline & SD & 34 & 79 & 71 & 78 & 63 & 73 & 51 & 63 & 79 & 34 & 64 \\
\hline & Mean & 15 & 62 & 39 & 57 & 38 & 60 & 44 & 59 & & & \\
\hline \multirow[t]{6}{*}{ Macrolides } & SPI & & 33 & 100 & 69 & 31 & 100 & 80 & & 100 & 31 & 69 \\
\hline & JOS & -9 & 100 & 72 & 74 & 48 & 100 & 26 & & 100 & -9 & 59 \\
\hline & TYL & & 29 & 100 & 46 & -61 & 100 & -57 & & 100 & -61 & 26 \\
\hline & ERY & 41 & 73 & -1 & 55 & -74 & 50 & -4 & 51 & 73 & -74 & 24 \\
\hline & ROX & -67 & 37 & 36 & 37 & -190 & -55 & -30 & -41 & 37 & -190 & -34 \\
\hline & Mean & -11 & 54 & 61 & 56 & -49 & 59 & 3 & 5 & & & \\
\hline
\end{tabular}

\footnotetext{
a Maximum

b Minimum.
}

STPs in the Pearl River Delta (Xu et al., 2007) and higher than the elimination (4.3\%) of ERY in STPs in Spain (Rosal et al., 2010). The removal efficiency of ROX ranged from -190 to $37 \%(-34 \%$ on average) in our study. The negative removal efficiency of macrolides by STPs had also been reported in previous works (Xu et al., 2007; Gulkowska et al., 2008). One of the possible reasons for these findings is that particles larger than $0.45 \mu \mathrm{m}$ are not included in the analysis, which may lead to an underestimation of the concentrations of the relevant compounds in the influents. Moreover, the conjugated metabolites in raw influent samples can be de-conjugated during the treatment process, or analyte behavior such as adsorption to particles may be altered by changing physicochemical parameters during the treatment process, thus influencing the removal efficiency (Lindberg et al., 2005; Xu et al., 2007).

The removal efficiency of antibiotics varied significantly among the eight STPs. STP C possessed the best removal capability for fluoroquinolones (86\%) and macrolides (61\%), and STP B possessed the best removal capability for sulfonamides (62\%). The worst removal capability was found at STP E for fluoroquinolones (8\%) and macrolides (-49\%), and at STP A for sulfonamides (15\%). The efficiency of the removal of antibiotics by an STP can be affected by the treatment process used, HRT and SRT, dilution and temperature of the raw sewage and the plant's configuration (Castiglioni et al., 2006; Göbel et al., 2007; Vieno et al., 2007; Gulkowska et al., 2008). In the present study, STP E applies $A^{2} / O$ technology and STP $C$ applies $A^{2} / O+C N R$ technology. It is possible that CNR technology in STP $C$ can cause the high removal efficiency of fluoroquinolones and macrolides. Compared with A/O (STP A), $A^{2} / O$ (STP B) technology may be more effective for the removal of sulfonamides. In this study, the HRT and SRT information are only available for four STPs (A, D, E, G) (Table S2). Among the four STPs, STP A, with the maximum SRT ( $20 \mathrm{~d})$, possessed the best removal capability for fluoroquinolones (80\%), and STP D, with the maximum HRT ( $15 \mathrm{~h})$, possessed the best removal capability for sulfonamides (57\%) and macrolides (56\%). Therefore, longer HRT and SRT may be more effective in the removal of antibiotics.

\subsection{Seasonal variation of antibiotics in sludge}

Seasonal variation of three types of antibiotics in sludge samples from seven STPs (except STP H) is shown in Fig. 1. The concentrations of three types of antibiotics in winter (January, 2008) were slightly higher than in spring (May, 2008) and autumn (September, 2008). Previous reports have also revealed that the level of antibiotics in the STP influents is greater in winter than in other seasons (Göbel et al., 2005; Castiglioni et al., 2006; Sui et al., 2011), indicating a higher consumption of antibiotics in winter. Furthermore, dilution of raw sewage by heavy rain has been noted to deteriorate the elimination of antibiotics in the sewage treatment (Vieno et al., 2007). However, this kind of dilution can be weakened greatly in winter. In addition, water consumption of urban residents usually declines in winter. Therefore, the antibiotics in raw sewage will be more prone to transfer from the aqueous to the solid phase in winter, causing an increase in the amount of antibiotics in the sludge.

\subsection{Potential toxic effect of fluoroquinolones to microorganisms in STPS}

As an important group of antibiotics, fluoroquinolones are widely used to treat a great deal of human and animal diseases. Fluoroquinolones have been proven to have genotoxic effects on genetically modified bacterial strain of Salmonella typhimurium at a concentration of $5.0 \mu \mathrm{g} \mathrm{L}^{-1}$ (Hartmann et al., 1998). Moreover, a PNEC of total fluoroquinolones for organisms in STPs is estimated to be $8.0 \mu \mathrm{g} \mathrm{L}^{-1}$ (Golet et al., 2002). In the present study, the concentrations of total fluoroquinolones in influents $\left(0.67-3.5 \mu \mathrm{g} \mathrm{L}^{-1}\right)$ were lower than the value of PNEC. Therefore, it is unlikely for fluoroquinolones to have adverse effects on microorganisms involved in sewage treatment processes. However, high concentrations of fluoroquinolones have been observed in sludge samples and further study is needed to assess their effects.

\section{Conclusions}

Out of 22 antibiotics, 14 were detected in the influents and effluents at the eight studied STPs, with OFL having the highest concentration in the influents $\left(3.1 \mu \mathrm{g} \mathrm{L}^{-1}\right)$ and effluents $\left(1.2 \mu \mathrm{g} \mathrm{L}^{-1}\right)$. The removal of antibiotics by the eight studied STPs is incomplete. Fluoroquinolones were removed relatively more efficiently than sulfonamides and macrolides. As for the occurrence in and removal of antibiotics from wastewater at the eight studied STPs, these were found to be similar to reports on other STPs. Antibiotics were also detected in sludge samples from the eight studied STPs. Fluoroquinolones were the dominant antibiotics in the sludge, and OFL has the highest concentration in all sludge samples, with the maximum 


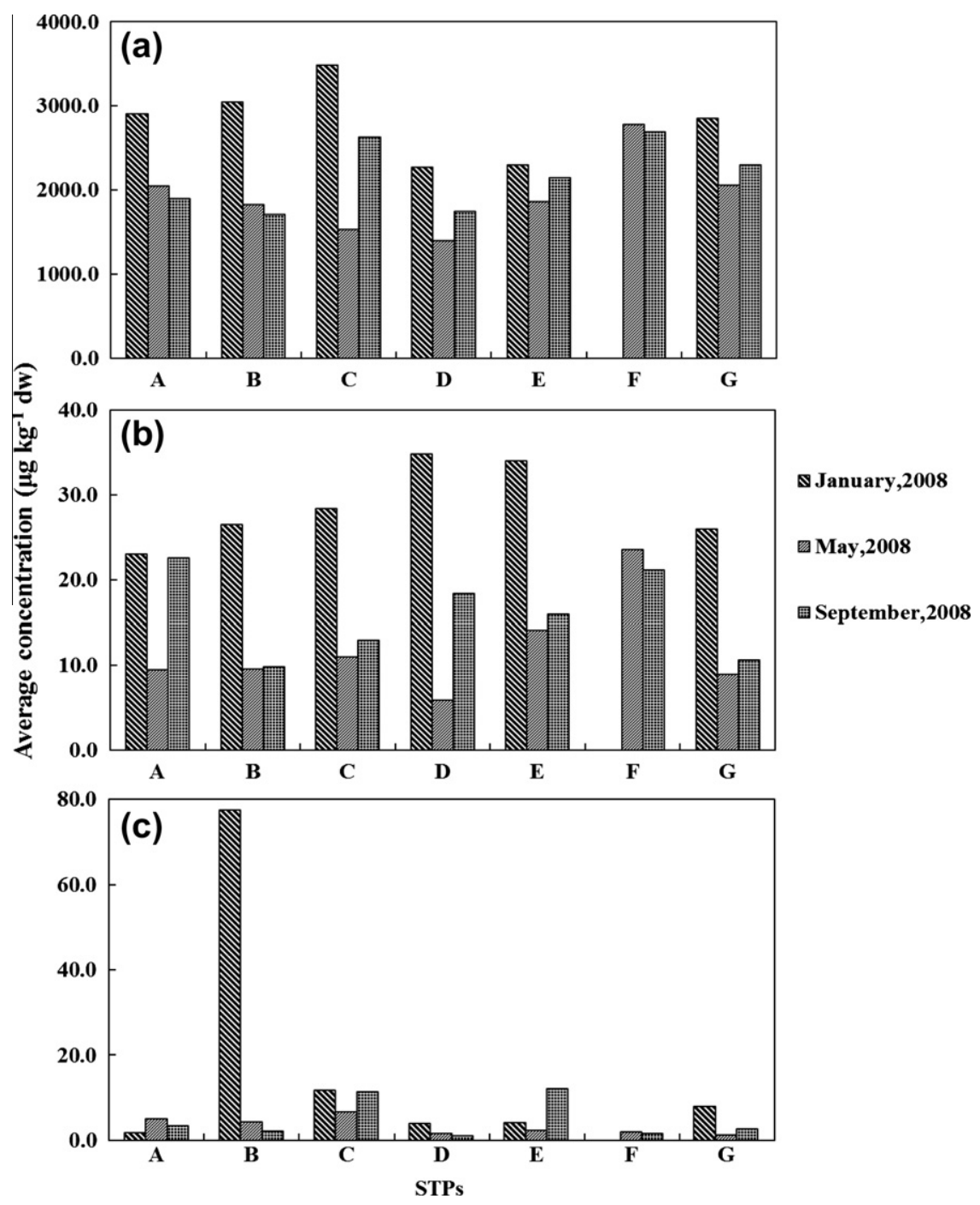

Fig. 1. Seasonal variation of fluoroquinolones (a), sulfonamides (b) and macrolides (c) in sludge samples from seven STPs.

concentration up to $2.1 \times 10^{4} \mu \mathrm{g} \mathrm{kg}^{-1} \mathrm{dw}$, which is much higher than those in previous studies. The concentrations of antibiotics are higher in winter than in spring and autumn. As found in the present study, the concentrations of total fluoroquinolones in the influents are not likely to have adverse effects on microorganisms involved in sewage treatment processes.

\section{Acknowledgments}

This work was financially supported by the National Natural Science Foundation of China (Nos. 20837003, 20921063, 20890111) and the National Basic Research Program of China (2009CB421605).

\section{Appendix A. Supplementary material}

Supplementary data associated with this article can be found, in the online version, at doi:10.1016/j.chemosphere.2011.11.019.

\section{References}

Castiglioni, S., Bagnati, R., Fanelli, R., Pomati, F., Calamari, D., Zuccato, E., 2006. Removal of pharmaceuticals in sewage treatment plants in Italy. Environ. Sci. Technol. 40, 357-363.
Chang, X., Meyer, M.T., Liu, X., Zhao, Q., Chen, H., Chen, J.-a., Qiu, Z., Yang, L., Cao, J. Shu, W., 2010. Determination of antibiotics in sewage from hospitals, nursery and slaughter house, wastewater treatment plant and source water in Chongqing region of Three Gorge Reservoir in China. Environ. Pollut. 158 1444-1450.

Costanzo, S., Murby, J., Bates, J., 2005. Ecosystem response to antibiotics entering the aquatic environment. Mar. Pollut. Bull. 51, 218-223.

Díaz-Cruz, M.S., Barceló, D., 2005. LC-MS ${ }^{2}$ trace analysis of antimicrobials in water, sediment and soil. TrAC, Trends Anal. Chem. 24, 645-657.

Gagné, F., Blaise, C., André, C., 2006. Occurrence of pharmaceutical products in a municipal effluent and toxicity to rainbow trout (Oncorhynchus mykiss) hepatocytes. Ecotoxicol. Environ. Saf. 64, 329-336.

Göbel, A., Thomsen, A., Mcardell, C.S., Joss, A., Giger, W., 2005. Occurrence and sorption behavior of sulfonamides, macrolides, and trimethoprim in activated sludge treatment. Environ. Sci. Technol. 39, 3981-3989.

Göbel, A., McArdell, C., Joss, A., Siegrist, H., Giger, W., 2007. Fate of sulfonamides, macrolides, and trimethoprim in different wastewater treatment technologies. Sci. Total Environ. 372, 361-371.

Golet, E.M. Alder, A.C. Giger, W. 2002. Environmental exposure and risk assessment of fluoroquinolone antibacterial agents in wastewater and river water of the Glatt valley watershed, Switzerland. Environ. Sci. Technol. 36 3645-3651.

Gulkowska, A. Leung, H.W., So, M.K., Taniyasu, S., Yamashita, N., Yeung, L.W.Y. Richardson, B.J., Lei, A.P., Giesy, J.P., Lam, P.K.S., 2008. Removal of antibiotics from wastewater by sewage treatment facilities in Hong Kong and Shenzhen, China. Water Res. 42, 395-403.

Hartmann, A., Alder, A.C., Koller, T., Widmer, R.M., 1998. Identification of fluoroquinolone antibiotics as the main source of umuC genotoxicity in native hospital wastewater. Environ. Toxicol. Chem. 17, 377-382.

Jiang, L., Hu, X., Yin, D., Zhang, H., Yu, Z., 2011. Occurrence, distribution and seasonal variation of antibiotics in the Huangpu River, Shanghai, China. Chemosphere 82, 822-828. 
Karthikeyan, K., Meyer, M., 2006. Occurrence of antibiotics in wastewater treatment facilities in Wisconsin, USA. Sci. Total Environ. 361, 196-207.

Khetan, S.K., Collins, T.J., 2007. Human pharmaceuticals in the aquatic environment: a challenge to green chemistry. Chem. Rev. 107, 2319-2364.

Kim, S.C., Carlson, K., 2007. Temporal and spatial trends in the occurrence of human and veterinary antibiotics in aqueous and river sediment matrices. Environ. Sci. Technol. 41, 50-57.

Kümmerer, K., 2009. Antibiotics in the aquatic environment - a review - Part I. Chemosphere 75, 417-434.

Li, B., Zhang, T., 2011. Mass flows and removal of antibiotics in two municipal wastewater treatment plants. Chemosphere 83, 1284-1289.

Lin, A.Y.-C., Yu, T.-H., Lateef, S.K., 2009. Removal of pharmaceuticals in secondary wastewater treatment processes in Taiwan. J. Hazard. Mater. 167, 11631169.

Lindberg, R., Jarnheimer, P., Olsen, B., Johansson, M., Tysklind, M., 2004. Determination of antibiotic substances in hospital sewage water using solid phase extraction and liquid chromatography/mass spectrometry and group analogue internal standards. Chemosphere 57, 1479-1488.

Lindberg, R.H., Wennberg, P., Johansson, M.I., Tysklind, M., Andersson, B.A.V., 2005. Screening of human antibiotic substances and determination of weekly mass flows in five sewage treatment plants in Sweden. Environ. Sci. Technol. 39, 3421-3429.

Lindsey, M.E., Meyer, M., Thurman, E.M., 2001. Analysis of trace levels of sulfonamide and tetracycline antimicrobials in groundwater and surface water using solid-phase extraction and liquid chromatography/mass spectrometry. Anal. Chem. 73, 4640-4646.

Löffler, D., Römbke, J., Meller, M., Ternes, T.A., 2005. Environmental fate of pharmaceuticals in water/sediment systems. Environ. Sci. Technol. 39, 52095218.

Loganathan, B., Phillips, M., Mowery, H., Jones-Lepp, T.L., 2009. Contamination profiles and mass loadings of macrolide antibiotics and illicit drugs from a small urban wastewater treatment plant. Chemosphere 75, 70-77.

McArdell, C.S., Molnar, E., Suter, M.J.F., Giger, W., 2003. Occurrence and fate of macrolide antibiotics in wastewater treatment plants and in the Glatt Valley watershed, Switzerland. Environ. Sci. Technol. 37, 5479-5486.
Okuda, T., Yamashita, N., Tanaka, H., Matsukawa, H., Tanabe, K., 2009. Development of extraction method of pharmaceuticals and their occurrences found in Japanese wastewater treatment plants. Environ. Int. 35, 815-820.

Rosal, R., Rodríguez, A., Perdigón-Melón, J.A., Petrea, A., García-Calvoa, E., Gómez, M.J., Agüera, A., Fernández-Alba, A.R., 2010. Occurrence of emerging pollutants in urban wastewater and their removal through biological treatment followed by ozonation. Water Res. 44, 578-588.

Sui, Q., Huang, J., Deng, S., Chen, W., Yu, G., 2011. Seasonal variation in the occurrence and removal of pharmaceuticals and personal care products in different biological wastewater treatment processes. Environ. Sci. Technol. 45, 3341-3348.

Ternes, T.A., Joss, A., Siegrist, H., 2004. Scrutinizing pharmaceuticals and personal care products in wastewater treatment. Environ. Sci. Technol. 38, 392A-399A.

USEPA, 2007. Method 1694: Pharmaceuticals and personal care products in water, soil, sediment, and biosolids by HPLC/MS/MS. <http://www.caslab.com/EPAMethods/PDF/1694.pdf>.

Vieno, N., Tuhkanen, T., Kronberg, L., 2007. Elimination of pharmaceuticals in sewage treatment plants in Finland. Water Res. 41, 1001-1012.

Watkinson, A.J., Murby, E.J., Costanzo, S.D., 2007. Removal of antibiotics in conventional and advanced wastewater treatment: Implications for environmental discharge and wastewater recycling. Water Res. 41, 4164-4176.

Wilson, B.A., Smith, V.H., deNoyelles, F., Larive, C.K., 2003. Effects of three pharmaceutical and personal care products on natural freshwater algal assemblages. Environ. Sci. Technol. 37, 1713-1719.

Xu, W., Zhang, G., Li, X., Zou, S., Li, P., Hu, Z., Li, J., 2007. Occurrence and elimination of antibiotics at four sewage treatment plants in the Pearl River Delta (PRD), South China. Water Res. 41, 4526-4534.

Yu, J., Bouwer, E., Coelhan, M., 2006. Occurrence and biodegradability studies of selected pharmaceuticals and personal care products in sewage effluent. Agric. Water Manage. 86, 72-80.

Zorita, S., Mårtensson, L., Mathiasson, L., 2009. Occurrence and removal of pharmaceuticals in a municipal sewage treatment system in the south of Sweden. Sci. Total Environ. 407, 2760-2770.

Zuccato, E., Castiglioni, S., Bagnati, R., Melis, M., Fanelli, R., 2010. Source, occurrence and fate of antibiotics in the Italian aquatic environment. J. Hazard. Mater. 179, 1042-1048. 